\title{
CONTRIBUIÇÃO AO ESTUDO DE UMA ARTE AMBIENTAL NA DÉCADA DE 1960
}

\author{
Marco Antonio Pasqualini de Andrade \\ Doutor em Artes pela ECA USP \\ Professor da Universidade Federal de Uberlândia
}

\section{O conceito de Ambiente}

O termo "ambiente" não possui, em si, um significado único e estático. É possível notar que sua conceituação se transforma de maneira marcante, especialmente ao longo dos anos de 1960.

O significado do termo admite uma variedade nas várias línguas, mas de modo geral relaciona-se com a idéia de um elemento que está imerso em um meio que o rodeia: no alemão, Umwelt (dentro do mundo); em inglês, environment (rodeado, revirado); em francês, environnement, ambient ou ambiance (circundante).

A orígem etmológica do termo em língua portuguesa deriva do latim ambire (andar ao redor, cercar, rodear). Aproxima-se da palavra âmbito (local, espaço). Segundo o Dicionário Houaiss, diz respeito a um "conjunto de condições materiais, culturais, psicológicas e morais que envolve uma ou mais pessoas; atmosfera".

Kenneth Friedman, buscando a orígem do termo environment, em inglês, encontra a definição: "De modo geral, todas as condições externas, físicas e socioculturais, que podem influenciar um indivíduo ou um grupo". Destaca que, às vezes, o termo parece se confundir, erroneamente, com a idéia de natureza e das questões ecológicas que evoca ${ }^{1}$.

Essa confusão, de fato, é fruto de uma transformação do conceito que se dará exatamente durante a década de 1960, e que envolve uma passagem do campo físico para o campo ecológico.

Se, em um primeiro momento, é possível afirmar que "ambiente" teria uma relação bastante próxima e vinculada a um dado da percepção psicológica do espaço e de determinados lugares, condicionada correlatamente ao fator tempo, ao longo da década de 60 a questão parece modificar seu rumo em direção a outros campos de conhecimento, em

\footnotetext{
${ }^{1}$ Kenneth S. Friedman. Words on the Environment. In: SONFIST, Allan (org.). Art in the Land. New York: E.P. Hutton, 1983, p. 253-6.
} 
especial ao seu caráter biológico, e amparado em uma conscientização cada vez mais aguda dos problemas sociais e mesmo higiênicos, vinculados a uma noção de habitat do homem e das estruturas ecológicas que interferem no seu estar no mundo.

Desse modo, a primeira concepção, que podemos crer apresenta raízes em várias disciplinas e teorias desenvolvidas no início do século XX, como a Gestalt e a fenomenologia de Heidegger, cria uma concepção de psicologia do ambiente, na qual os elementos estruturais seriam o espaço, a forma, a luz, a cor e o tempo. A questão estética mostra-se predominante, no sentido da experimentação das sensações e de sua demarcação por diferentes modos de ver, de sentir, de perceber, de portar-se e imaginar-se em um dado espaço, concebido eminentemente como físico.

A segunda concepção traz uma série de elementos novos, e vincula-se ao advento da consciência do problema do lixo e da poluição nas grandes cidades, dos restos da sociedade de consumo que resistem à sua rápida depreciação, permanecendo como índices retalhados e gastos do habitar civilizatório, impondo sua presença e exigindo uma posição quanto ao seu fim e suas conseqüências. O desperdício dos bens não duráveis e efêmeros traz uma demanda pela reciclagem, reaproveitamento das sobras, a criação de uma segunda vida rearticulada ao produto humano. As questões antropológicas, ecológicas e sociais se tornarão predominantes e urgentes, criando nos anos de 1970, uma série de movimentos políticos de reivindicação de soluções dirigidos aos partidos políticos e aos governos instalados, principalmente a partir da grande crise energética e do petróleo de 1973-4.

É possível entender que, já durante os anos 60, a passagem do físico ao ecológico se dá por uma questão intermediária e fundamental: o dado social e, de modo mais explícito, o público.

Robert Mugerauer conceitua a noção de ambiente a partir da origem da palavra "natureza". Para os antigos gregos, a idéia de physis era relacionada a uma concepção da natureza como energia, ato gerador e transformador, enquanto que a palavra latina natura indica uma visão mais estática e idealizada da natureza como algo idílico, primitivo, virgem, intocado ${ }^{2}$.

2 Robert Mugerauer. Interpreting Environments: tradition, deconstruction, hermeneutics. Austin: University of Texas Press, 1995, p. 109-110. 
A predominância da segunda visão gerou uma concepção de preservacionismo, que tende a tentar deter a marcha civilizatória humana, propondo um retorno a uma condição idílica e utópica de um paraíso perdido $^{3}$. Os grupos chamados ambientalistas, situando-se em tal concepção, recusam-se a ver a natureza como uma construção social e discursiva dinâmica, que seria impossível de ser dissociada da própria civilização enquanto evolução histórica. Afinal, qual seria a função e o significado de preservar a natureza? Qual natureza?

Para interpretar esse ambiente podemos pensar, segundo Mugerauer, em quatro possibilidades de abrangência ou análise do problema: o ambiente natural ou biológico; o ambiente cultural ou construído; o ambiente histórico ou temporal; e o ambiente lingüístico ou sígnico. A noção de ambiente envolve a complexidade dessas múltiplas visões e, dessa forma, objetiva ampliar o entendimento das propostas artísticas derivadas da noção de ambiental.

Um autor que parece ser fundamental para essa compreensão é o historiador da arte Giulio Carlo Argan. Para Argan, o ambiente não admite nenhuma definição racional ou geométrica, e se concretiza em uma série de relações e interações entre realidade psicológica e realidade física. Não pode ser estruturado, nem projetado, mas poderia ser pensado a partir de um diagrama, no qual seria possível verificar a regularidade ou a descrição de um processo em termos matemáticos. Por esta visão, baseada no estruturalista Alexander, a cidade funciona como uma linguagem, um campo de trocas e consumo de informações. A possibilidade de liberdade se daria, desta forma, em não consumir, ou modificar os modos de consumo, criando jogos em que as coisas possam se converter em imagens, que são difusas, imprecisas, mutáveis'.

A antiga relação entre a cidade (a construção organizada e culta), o campo (o arcaico e o ritual) e a natureza (lugar do mito e do sagrado), se desfaz na época contempoânea. A noção de espaço, que implicava uma diferenciação entre o "eu" (o ego) e a "natureza" (o sublime), perde significado no momento em que a cidade aumenta seu potencial mecânico e tecnológico. Torna-se um novo campo para o sublime, e gera o sentimento

3 SOULÉ, Michael E.; LEASE, Gary (org.) Reinventing Nature? Responses to post modern deconstruction. Washigton-DC: Island Press, 1995.

${ }^{4}$ Giulio Carlo Argan. Urbanismo, espaço e ambiente. In: História da arte como história da cidade. São Paulo: Martis Fontes, 2005, p. 215-219. 
de angústia contemporâneo. A realidade perde a escala humana, na medida em que só pode ser dominada ou sofrida, e portanto alterna-se uma relação entre o infinitamente grande e o infinitamente pequeno, no qual o indivíduo desaparece na massa e a natureza não tem mais razão de ser. ${ }^{5}$

Argan defende que as artes visuais se transformem em urbanismo (assim como o campo da arquitetura), ou melhor, que aconteça "a integração das artes visuais na empresa urbanística”. Isso seria traduzido, em um primeiro momento, como "desenho industrial", ou design. Porém, apesar das iniciativas de artistas modernos, como Klee, Kandinsky, Mondrian, Albers e Moholy-Nagy, a preferência de permanecerem como "intelectuais de oposição", nas palavras do autor, assim como a posterior onda neo-romântica do Informal, atrasaram esse projeto. Para conviver com a realidade da cidade-consumo e de sua crise, criou-se uma arte de não-produto (não-objeto?), de contestação do sistema.

Uma arte para consumir, ou já consumida de imediato, impede a percepção, que torna-se supérflua e vira pura informação, uma "estética do acontecimento". E o objeto de arte revela-se artificial, urbano, interpretável e histórico. Mas a cidade é, acima de tudo, a dimensão da existência, feita de imagens, sensações, de impulsos mentais. "Esta é a cidade que vemos; este é o ambiente completo, o ambiente físico - diria Alexander - no qual vivemos"6.

Neste texto, escrito em 1969, Argan conclui definindo algo que, de maneira impressionante, se aproxima muito das propostas de Hélio Oiticica e Mário Pedrosa para uma arte ambiental:

Hoje, é componente do espaço urbanístico qualquer coisa que, na contínua mutação da realidade ambiental, retém por um instante nossa atenção, obriga-nos a reconhecer-nos (ainda que para tomar consciência de nossa nulidade) em um objeto ou em algo que, não sendo objeto no sentido tradicional do termo, ainda é algo que não conhecemos e cuja chave, cujo código de interpretação devemos encontrar. Todas as pesquisas visuais deveriam ser organizadas como pesquisa urbanística. [...] Mas é este o fim a que deveria visar uma arte que fosse consciente de ser e dever ser, como sempre foi, um fato de cultura urbana, e cuja teoria, mais ainda do que uma estética, seria um urbanismo geral. ${ }^{7}$

Mas, a noção de "ambiente", como é utilizado dentro do meio artístico, surgiu anteriormente à proposta de Hélio Oiticica, por intermédio

\footnotetext{
${ }^{5}$ Giulio Carlo Argan. Op.cit., p. 213-214.

${ }^{6}$ Giulio Carlo Argan, op. Cit., p.223.

${ }^{7}$ Giulio Carlo Argan, op. Cit., p.224.
} 
de artistas europeus e norte-americanos. Devemos, portanto, nos remeter a esse contexto internacional.

\section{Environmental Art}

Segundo Alfred Pacquement, arte ambiental (environmental art) seria "uma forma de arte baseada na premissa de que um trabalho de arte deveria invadir a totalidade da arquitetura a seu redor e ser concebida como um espaço completo, mais do que ser reduzida a um mero objeto pendurado na parede ou disposto em um espaço"8.

Referindo-se às pinturas de antigas tumbas, aos afrescos romanos e renascentistas e às pinturas das capelas barrocas como alguns antecedentes (e de modo mais abrangente a toda forma de arte anterior ao surgimento do quadro e da escultura móvel), o autor coloca o problema ligado especificamente ao questionamento dos suportes tradicionais da arte.

Neste aspecto, cita os estudos cênicos do futurista Balla; o Café Pittoresque dos construtivistas Rodchenko, Tatlin e Yakulov, de 1917; o complexo Aubette em Estrasburgo, de Arp, Taeuber-Arp e Van Doesburg de 1926; o uso do espaço na galeria Diemen de Berlim por El Lissitsky em 1923; o estúdio de Mondrian de Paris; os vários Merz̧ban de Kurt Schwitters; e a exposição Ambiente Spaziale de Lucio Fontana na Galeria Naviglio de Milão em 1949.

Sobre essa última, em depoimentos de críticos da época, é possivel localizar uma primeira abordagem desse tema:

A Galeria naquela ocasião se transformou; o teto foi colorido por uma luz violácea, plena de penumbra, na qual foram suspensas formas espaciais que pareciam ramos de árvores em fundo marinho, ou recifes suspensos no ar, mas 'ambientados'; e quando entrava neste ambiente, o espectador se via atraído; não contemplava uma forma parada, diante de seus olhos, entrava em um ambiente pictórico. Poder-se-ia pensar em uma cenografia: mas não se tratava de uma verdadeira cenografia. Era como entrar em uma grande cerâmica do próprio Fontana. ${ }^{9}$

No Ambiente Espacial havia [...] formas plásticas abstratas presas ao teto, com um efeito de aparições flutuantes no escuro, devido à iluminação com luz fluorescente. Em suma, não era uma grande coisa; mas representava a tentativa de uma arte ambiental na qual o espectador podia entrar e na qual poderia sentir-se circundado. ${ }^{10}$

\footnotetext{
8 Alfred Pacquement. Environmental Art. In: TURNER, Jane (org.) Groove's Dictionary of Art. London: 1994, v.10, p.415.

${ }_{9}^{9}$ Guido Ballo, apud Luciano Colavero. L'avvento dello spazialismo: gli Ambiente Spaziali. Disponínel em: www.geocities.com/Athens/Agora/5156/cap6.htm. Acesso em 26 dez. 2006.

${ }^{10}$ Giorgio De Marchis, apud Luciano Colavero, op. cit.
} 
Tais iniciativas têm em comum a questão de teorias advindas da prática pictórica, inserindo-as em um totum espacial no qual o espectador imerge, como que mergulhado em luz e cor.

É possível que Allan Kaprow tenha sido o primeiro artista norteamericano a usar o termo inglês environment dentro de um contexto artístico. Anne Rorimer indica justamente o texto "O Legado de Jackson Pollock", publicado na revista Art News de outubro de 1953, no qual este comenta as pinturas em escala mural de Pollock ${ }^{11}$. Para Kaprow, elas "deixaram de se tornar pinturas e se transformaram em ambientes"12. Comentando a possibilidade da inserção do espaço e dos objetos do dia a dia, propõe que "devemos utilizar a substância específicas da visão, do som, dos movimentos, das pessoas, dos odores, do tato"13.

Rorimer vê uma correspondência entre a noção de ambiente e a de assemblage, termo cunhado também em 1953 por Jean Dubuffet para designar obras tridimensionais que usariam materiais e objetos não artísticos, e que levariam às propostas dos happenings de Kaprow de 195914.

Kaprow define assim os environments:

Environments são de modo geral situações tranquilas, existindo para uma ou várias pessoas andarem ou rastejarem dentro, se deitarem, ou sentarem. Alguém olha, às vezes escuta, come, bebe, ou rearranja os elementos como se mudasse de lugar os móveis de casa. Outros environments pedem que o participante-visitante recrie e continue os processos inerentes ao trabalho. Para os seres humanos finalmente, todas essas características sugerem algum procedimento meditativo ou pensante. ${ }^{15}$

Pacquement também coloca a emergência do termo dentro da prática da performance e dos happenings, com seus antecedentes tomados da exposição surrealista de 1942 em Nova Iorque, quando Marcel Duchamp criou um emaranhado de fios que atravessavam o espaço, interligando as obras. As iniciativas de Yves Klein (O Vazio, 1958) e Arman (O Pleno, 1960) na Galeria Íris Clert de Paris, assim como a de Allan Kaprow (Jardim, 1961) na Galeria Martha Jackson de Nova Iorque, seriam marcantes, pois se

\footnotetext{
${ }^{11}$ Anne Rorimer. New Art in the 60s and 70s: redefining reality. London: Thames \& Hudson, 2001, p. 277.

12 Allan Kaprow. O legado de Jackson Pollock. In: FERREIRA, Glória; COTRIM, Cecília (Org.) Escritos de Artistas: anos 60/70. Rio de Janeiro: Jorge Zahar, 2006, p.42.

13 Allan Kaprow, op. cit., p.44.

${ }_{14}$ Anne Rorimer, op. cit., p. 32.

15 Allan Kaprow. Assemblages, Environmnts and Happenings. In: HARRISON, Charles; WOOD, Paul (Org.) Art in Theory 1900-1990: an Anthology of Changing Ideas. Oxford, Cambridge: Blackwell, 1994, p.705.
} 
colocavam como provocações efêmeras e não comerciais ao circuito de arte.

Por outro lado, a noção de ambiente também seria atribuída a propostas artísticas nas quais a ênfase seria deslocada para fatores ópticos e sonoros do espaço. Os Penetráveis de Jesus-Raphael Soto (1969), cubos de tubos plásticos no qual o espectador poderia entrar, observar e ser observado. As iniciativas do Grupo de Pesquisas de Arte Visual, na França, dos italianos Alviani, Colombo e Castellani ou de Takis também caminhariam nesse sentido.

Mais tarde, segundo Pacquement, poderiam ser inseridas nesse tipo de arte as obras concebidas para o espaço de Joseph Beuys, dos artistas da Arte Povera italiana e dos minimalistas norte-americanos. Termos correlatos, como o in situ de Daniel Buren ou a noção de site -specific, presente em obras de Richard Serra, Walter De Maria ou Bruce Nauman, dariam outros passos em direção ao que hoje, de forma mais abrangente, poderia ser chamado de "instalação".

Um outro autor que situa o problema é Simon Marchán. Para ele, o ambiente, além de afetar a atividade sensorial do espectador, permite que este seja mergulhado em um movimento de participação e impulsionado a um comportamento exploratório do espaço que o rodeia e dos objetos inseridos neste espaço. ${ }^{16}$

Marchán identifica a origem de uma arte ambiental nas construções derivadas das collages e ligadas a uma arte total, como o Meræ̧a de Kurt Schwitters, e também no produtivismo dos espaços Prounen de El Lissitzky, que intencionavam a uma integração das artes. Arte ambiental e arte objetual teriam um surgimento simultâneo, e seu desenvolvimento, no final dos anos 50, atestaria esse fato, através principalmente dos primeiros environments de Allan Kaprow, de 1958, baseados numa expansão do conceito de assemblage, o que coincide com o pensamento de Anne Rorimer.

\section{O Programa Ambiental de Oiticica}

Há uma aproximação do conceito de arte ambiental de Hélio Oiticica às iniciativas internacionais, seja no princípio de expandir o objeto de arte a seu entorno, de ampliar a percepção sensorial do espectador, ou de

\footnotetext{
${ }^{16}$ MARCHÁN, Simon. Del arte objetual al arte de concepto. 2 ed. Madrid: Alberto Corazón, 1974, p. 205.
} 
recuperar os signos culturais do cotidiano, que resultam na integração entre o homem e seu ambiente.

A inserção no Brasil do termo ambiente, no âmbito das artes visuais, ou arte ambiental, deve-se pioneiramente ao artista carioca Hélio Oiticica, que escreve em 1964, vinculado à proposição dos seus Parangolés:

Nessa procura de uma fundação objetiva, de um novo espaço e um novo tempo na obra no espaço ambiental, almeja esse sentido construtivo do Parangolé a uma "arte ambiental" por excelência, que poderia ou não chegar a uma arquitetura característica. Há como que uma hierarquia de ordens na plasmação experimental de Núcleos, Penetráveis e Bólides, todas elas, porém, dirigidas para essa criação de um mundo ambiental onde essa estrutura da obra se desenvolva e teça a sua trama original. A participação do espectador é também aqui característica em relação ao que hoje existe na arte em geral: é uma "participação ambiental" por excelência. Trata-se da procura de "totalidades ambientais" que seriam criadas e exploradas em todas as suas ordens, desde o infinitamente pequeno até o espaço arquitetônico, urbano, etc. ${ }^{17}$

Nota-se que o artista estabelece um vínculo da "obra" com o entorno, através do espectador. Essa "obra" que ativa o espaço circundante, preenche o "vazio", e pode ser de qualquer natureza ou dimensão. Deve-se utililizar para constituir essa "obra" objetos existentes no espaço habitado, seja urbano ou rural:

Também a "tenda" é erigida pela relação ambiental que exige aqui um 'percurso do espectador', um desvendamento da sua estrutura pela ação corporal direta do espectador. Essa relação é pois contingente, inevitável e perfeitamente coerente dentro da dialética do "Parangolé". O "achar" na paisagem do mundo urbano, rural, etc., elementos "Parangolé" está aí também incluído como o 'estabelecer relações perceptivo-estruturais' do que cresce na trama estrutural do "Parangolé" (que representa aqui o caráter geral da estrutura-cor no espaço ambiental) e o que é "achado" no mundo espacial ambiental. ${ }^{18}$

Oiticica reporta-se a um texto seu, publicado em dezembro de 1962 na revista Habitat, no qual desenvolve questões sobre a inserção da estrutura-cor no espaço e no tempo. Nesse texto, relata como, desde suas obras monocromáticas e as Invenções de 1959, iniciou uma busca de conquista do espaço pelas pinturas, o que se desenvolveria nos Núcleos e nos Penetráveis, a partir de 1960. Citando as produções de uma série de artistas, que inclui os construtivistas, Pollock, Fontana e Yves Klein, o artista fala da experiência da tridimensionalidade, da passagem para o

\footnotetext{
${ }^{17}$ Helio Oiticica. Novembro 1964. Bases fundamentais para uma definição do "Parangolé". In: Aspiro ao grande labirinto. Rio de Janeiro: Rocco, 1986, p. 67.

${ }^{18}$ Idem.
} 
espaço e o tempo e da superação da idéia de suporte. No Penetrável, especialmente,

... a relação entre o espectador e a estrutura-cor se dá numa integração completa, pois que virtualmente é ele colocado no centro da mesma. Aqui a visão cíclica do núcleo pode ser considerada como uma visão global ou esférica, pois que a cor se desenvolve em placas verticais e horizontais, no chão e no teto. ${ }^{19}$

A relação com todo o espaço circundante já se encontra estabelecido, de modo a promover a percepção sensorial das matérias e do vazio.

O fio do desenvolvimento estrutura-cor se desenrola aqui acrescido de novas virtualidades muito mais completo, onde o sentido de envolvimento atinge o seu auge e sua justificação. O sentido de apreender o 'vazio' que se insinuou nas Invenções chega a sua plenitude através da valorização de todos os recantos do penetrável, inclusive o que é pisado pelo espectador, que por sua vez já se transformou no 'descobridor da obra', desvendando-a parte por parte..$^{20}$

O dado fenomenológico, no qual são abandonados os códigos do mundo em nome de uma nova sensibilização do espectador, a partir do zero, é adotado como caminho para chegar a uma "arte pura".

Para mim a invenção do penetrável além de gerar a dos projetos, abre campo para uma região completamente inexplorada da arte da cor, introduzindo aí um caráter coletivista e cósmico e tornando mais clara a intenção de toda essa experiência no sentido de transformar o que há de imediato na vivência cotidiana em não-imediato; em eliminar toda relação de representação e conceituação que porventura haja carregado em si a arte. $\mathrm{O}$ sentido de arte pura atinge aqui sua justificação lógica. ${ }^{21}$

Há pois, para Oiticica, uma correlação entre a noção de "penetrável" e a de "arte ambiental", porém nota-se que esta última abrange para o artista muito mais que uma imersão física no espaço, desdobrando-se para uma apropriação de dados culturais que envolvem a música, a dança, o contexto sócio-econômico e antropológico do espectador / participante da obra.

Para o historiador de arte e filósofo Celso Favaretto, “o ambiental é uma modalidade da atividade desestetizadora, empenhada no questionamento das categorias habituais da arte e do circuito. Efetua uma mutação dos conceitos e dos procedimentos, desterritorializa os

\footnotetext{
${ }^{19}$ Hélio Oiticica. A transição da cor do quadro para o espaço e o sentido de construtividade. Habitat, São Paulo, ano 12, n.70, dez. 1962, p. 51.

${ }^{20}$ Idem.

${ }^{21}$ Idem.
} 
participantes e proscreve as obras de arte". Seriam elementos comuns da arte ambiental: "sentidos arquitetônico (especulativo, visionário, utópico), expressivo (individual e coletivo) e social (ético-político)"22.

É por essa visão que Oiticica usa sempre a noção de "programa ambiental" ou "manifestações ambientais", mais do que "arte ambiental", esta última configurando-se mais como uma categoria de trabalho artístico, portanto passível de render-se facilmente às classificações do circuito de arte de vanguarda. É pelo mesmo motivo que usa o termo "experimental" de modo isolado, diferenciando de "arte experimental", que ao classificar-se como "arte" já perderia muito de seu potencial enunciativo. Favaretto, ao comentar sua obra, prefere falar de uma "antiarte ambiental", para enfatizar esta recusa ao ajustamento fácil com as tendências artísticas então em voga.

O crítico de arte Mário Pedrosa, em junho de 1966, escrevendo sobre Oiticica, acaba por utilizar de fato a denominação arte ambiental, que será posteriormente aplicada, por ele e outros críticos, a outros artistas.

Arte ambiental é como Oiticica chamou sua arte. Não é com efeito outra coisa. Nela nada é isolado. Não há uma obra que se aprecie em si mesma, como um quadro. O conjunto perceptivo sensorial domina. Nesse conjunto criou o artista uma 'hierarquia de ordens' - relevos, núcleos, bólides (caixas) e capas, estandartes, tendas ('parangolés') - 'todas dirigidas para a criação de um mundo ambiental'. Foi durante a iniciação ao samba, que o artista passou da experiência visual, em sua pureza, para uma experiência do tato, do movimento, da fruição sensual dos materiais, em que o corpo inteiro, antes resumido na aristocracia distante do visual, entra como fonte total da sensorialidade. [...] Dir-se-ia que o artista passa às mãos que tateiam e mergulham, por vezes enluvadas, em pó, em carvão, em conchas, a mensagem de rigor, de luxo e exaltação que a visão nos dava. Assim ele deu a volta toda ao círculo da gama sensorial-tátil, motora. A ambiência é de saturação virtual, sensória. O artista se vê agora, pela primeira vez, em face de outra realidade, o mundo da consciência, dos estados de alma, o mundo dos valores. Tudo tem de ser agora enquadrado num comportamento significativo. Com efeito, a pura e crua totalidade sensorial, tão deliberadamente procurada e tão decisivamente importante na arte de Oiticica, é afinal marejada pela transcendência a outro ambiente. Neste, o artista, máquina sensorial absoluta, baqueia vencido pelo homem, convulsivamente preso nas paixões sujas do ego e na trágica dialética do encontro social."’23

Pensando nessa outra realidade "o mundo da consciência, dos estados de alma, o mundo dos valores”, em outra ocasião, ampliando o alcance da questão para além da obra de Hélio Oiticica, afirma o crítico:

A arte ambiental no Brasil, de que foi no mundo um dos países precursores, caracteriza-se sobretudo por ser vivencial e por nunca se ter embarafustado (a não ser posteriormente, sobretudo em São Paulo)

22 Celso Favaretto. A Invenção de Hélio Oiticica. São Paulo: Edusp/Fapesp, 2000, p.125-7.

${ }^{23}$ Mário Pedrosa. Arte ambiental, arte pós-moderna, Hélio Oiticica. In: Dos Murais de Portinari aos espaços de Brasília. São Paulo: Perspectiva, 1981, p.207-8. 
pela outra modalidade ambiental que é a ambiental abstrata, reflexo das virtualidades tecnológicas da civilização industrial. [...] E a novíssima geração que já aponta prossegue na trilha da ambiência urbana carioca, embora ainda mais despojada de meios técnicos, mais adstrita aos recursos próprios diretos apropriáveis, à pobreza, a uma consciência grupal menos aberta ou idealista, ou mais radical"24

É perceptível como Pedrosa aponta tanto para o fato de haver mais de uma geração investigando o problema da arte ambiental, como de uma diferenciação entre um viés mais vivencial (carioca) e um mais tecnológico (presente em São Paulo). Além disso, relaciona a nova geração ao uso e apropriação de materiais e situações "pobres", e à sua radicalidade. O crítico se refere, especificamente, aos artistas surgidos no circuito no final da década de 1960, ou seja, Artur Barrio, Antonio Manuel, Guilherme Vaz e Cildo Meireles, entre outros.

É nesse sentido que, quando Mário Pedrosa e Mário Schenberg se referem a esta nova geração como "artistas ambientais", estão trazendo à tona os princípios fundamentais da proposta de Oiticica. E embora "ambiente" possa remeter a um lugar que envolva o espectador, em grande escala, uma obra ou experiência "ambiental" significa algo muito mais complexo, ou seja, a inserção do espectador em uma relação com o urbano, seja pelo objeto, pelo contexto, pela imagem, ou pela comunicação informativa.

${ }^{24}$ Mário Pedrosa. A Bienal de cá para lá. In: GULLAR, Ferreira. Arte Brasileira Hoje. Rio de janeiro: Paz e Terra, 1973, p.62. 